From the Erasmus Medical Center Daniel den Hoed Cancer Center, Rotterdam; Family Cancer Clinic, Netherlands Cancer Institute/Antoni van Leeuwenhoek Hospital, Amsterdam; Free University Medical Center, Amsterdam; Radboud University Medical Center and Hereditary Cancer Clinic, Nijmegen; Leiden University Medical Center, Leiden; and the Groningen University Medical Center, Groningen University, Groningen, the Netherlands.

Submitted November 23, 2009; accepted September 1, 2010; published online ahead of print at www.jco.org on November 15, 2010

Written on behalf of the MRI Screening Study Group.

Supported Grant No. ZON-MW: 6200.0005 by the Dutch government and the Cancer Genomics Center (C.G.C.), the Netherlands.

†Deceased.

Authors' disclosures of potential conflicts of interest and author contributions are found at the end of this article.

Corresponding author: Jan G.M. Klijn, MD, PhD, Erasmus MC, Daniel den Hoed Cancer Center, Groene Hilledijk 301, 3075 EA, Rotterdam, the Netherlands; e-mail: j.g.m.klijn@erasmusmc.nl.

(c) 2010 by American Society of Clinica Oncology

0732-183X/10/2836-5265/\$20.00

DOI: 10.1200/JCO.2009.27.2294

\title{
BRCA1-Associated Breast Cancers Present Differently From BRCA2-Associated and Familial Cases: Long-Term Follow-Up of the Dutch MRISC Screening Study
}

Adriana J. Rijnsburger, Inge-Marie Obdeijn, Reinoutje Kaas, Madeleine M.A. Tilanus-Linthorst, Carla Boetes, Claudette E. Loo, Martin N.J.M. Wasser, Elisabeth Bergers, Theo Kok, Sara H. Muller, Hans Peterse, $\dagger$ Rob A.E.M. Tollenaar, Nicoline Hoogerbrugge, Sybren Meijer, Carina C.M. Bartels, Caroline Seynaeve, Maartje J. Hooning, Mieke Kriege, Paul I. M. Schmitz, Jan C. Oosterwijk, Harry J. de Koning, Emiel J.T. Rutgers, and Jan G.M. Klijn

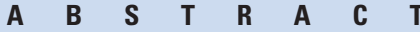

\section{Purpose}

The Dutch MRI Screening Study on early detection of hereditary breast cancer started in 1999. We evaluated the long-term results including separate analyses of BRCA1 and BRCA2 mutation carriers and first results on survival.

\section{Patients and Methods}

Women with higher than 15\% cumulative lifetime risk (CLTR) of breast cancer were screened with biannual clinical breast examination and annual mammography and magnetic resonance imaging (MRI). Participants were divided into subgroups: carriers of a gene mutation (50\% to $85 \%$ CLTR) and two familial groups with high (30\% to 50\% CLTR) or moderate risk (15\% to 30\% CLTR).

\section{Results}

Our update contains 2,157 eligible women including 599 mutation carriers (median follow-up of 4.9 years from entry) with 97 primary breast cancers detected (median follow-up of 5.0 years from diagnosis). MRI sensitivity was superior to that of mammography for invasive cancer $(77.4 \% \mathrm{~V}$ $35.5 \% ; P<.00005)$, but not for ductal carcinoma in situ. Results in the BRCA1 group were worse compared to the BRCA2, the high-, and the moderate-risk groups, respectively, for mammography sensitivity $(25.0 \% \vee 61.5 \%, 45.5 \%, 46.7 \%)$, tumor size at diagnosis $\leq 1 \mathrm{~cm}(21.4 \% \vee 61.5 \%$, $40.9 \%, 63.6 \%)$, proportion of DCIS $(6.5 \% \vee 18.8 \%, 14.8 \%, 31.3 \%)$ and interval cancers $(32.3 \% \vee$ $6.3 \%, 3.7 \%, 6.3 \%)$, and age at diagnosis younger than 30 years $(9.7 \% \vee 0 \%)$. Cumulative distant metastasis-free and overall survival at 6 years in all 42 BRCA1/2 mutation carriers with invasive breast cancer were $83.9 \%(95 \% \mathrm{Cl}, 64.1 \%$ to $93.3 \%)$ and $92.7 \%(95 \% \mathrm{Cl}, 79.0 \%$ to $97.6 \%)$, respectively, and $100 \%$ in the familial groups $(n=43)$.

\section{Conclusion}

Screening results were somewhat worse in BRCA1 mutation carriers, but 6-year survival was high in all risk groups.

\section{J Clin Oncol 28:5265-5273. (C) 2010 by American Society of Clinical Oncology}

\section{INTRODUCTION}

Women with a genetic predisposition for breast cancer face a cumulative lifetime risk (CLTR) of breast cancer varying between $15 \%$ and $85 \% .^{1-4}$ The risk of breast cancer can be reduced by prophylactic surgery or chemoprevention. ${ }^{5-9}$ A promising strategy to reduce the risk of breast cancer death is early diagnosis by intensive surveillance. First results of various large prospective studies have shown that magnetic resonance imaging (MRI) appears to be about twice as sensitive as mammography in detecting tumors in women with a susceptibility to breast cancer. ${ }^{10-21} \mathrm{Al}$ - though most guidelines now recommend MRI screening in BRCA1/2 mutation carriers, ${ }^{22-24}$ no consensus on the screening protocol exists for all risk groups. Only a few (small) studies investigated screening results in BRCA1 and BRCA2 mutation carriers separately. Furthermore, data on mortality are lacking.

Therefore, based on an extensive update and enlargement of our MRI Screening Study (MRISC), the largest $(n=2,157)$ in the world to our knowledge, the objectives of our current study were: evaluation of screening effects in four different genetic risk groups focusing on (potential) differences between BRCA1 and BRCA2 mutation carriers and to 
study, for the first time to our knowledge, effects on observed breast cancer mortality.

\section{PATIENTS AND METHODS}

\section{Study Population}

The Dutch MRISC study is a nonrandomized prospective cohort study. Between November 1, 1999, and March 1, 2006, 2,275 women with a genetic risk of breast cancer were enrolled by six cancer and/or university centers (Appendix Table A1, online only). The study was approved by the ethics committees of all centers. All women provided written informed consent.

Women (age, 25 to 75 years) with a cumulative lifetime risk (CLTR) of developing breast cancer of $\geq 15 \%$ due to a familial or genetic predisposition were eligible for the study. ${ }^{10,25}$ Women with symptoms or a personal history of breast cancer were excluded. At study entry, participants were divided into subgroups according to their estimated CLTR of breast cancer: carriers of $B R C A 1, B R C A 2$, or other mutations (50\% to $85 \%$ CLTR), a high-risk group ( $30 \%$ to $50 \%$ CLTR), and a moderate-risk group ( $15 \%$ to $30 \%$ CLTR) without a documented gene mutation. These CLTR categories for breast cancer were based on the modified tables of Claus. ${ }^{4,25}$

\section{Study Protocol}

Participating women were screened with biannual clinical breast examination (CBE) and annual (simultaneous) two-view mammography and MRI of the breasts. Through the years, all centers changed from conventional to digital mammography. In all centers, dynamic contrast enhanced MRI was performed on a 1.5 Tesla system (Siemens, Erlangen, Germany). Breast MRI workstations were used to perform time-signal intensity curves. During the study, the MR units were upgraded and scanning protocols improved. The mammography and MRI were scored in a standardized way according to the Breast Imaging Reporting and Data System (BI-RADS), ${ }^{26,27}$ and were independently evaluated. We defined as positive a mammography or MRI with

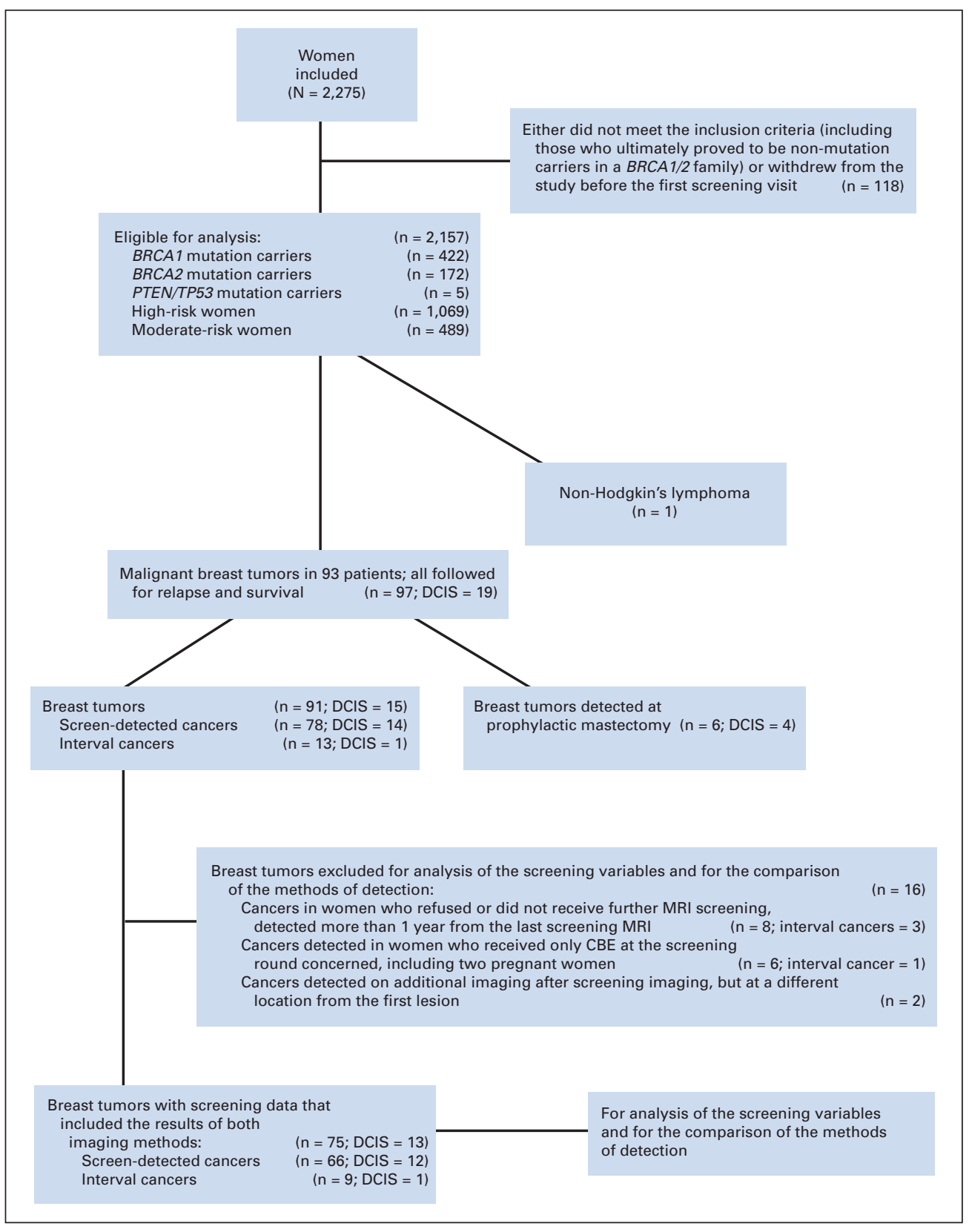

Fig 1. Flow chart describing the number of women and number of breast tumors available for statistical analysis. The numbers of DCIS and interval cancers are included in the total number of breast tumors. DCIS, ductal carcinoma in situ; MRI, magnetic resonance imaging; $\mathrm{CBE}$, clinical breast examination. 
BI-RADS score 3, 0, 4, or 5 and a CBE that was classified as uncertain or suspicious, because those were the results that triggered an additional examination. An interval cancer was defined as a carcinoma detected by the woman between two rounds of screening, after initially negative findings on screening. The diagnosis of a malignant tumor was based on the results of histologic examination. Patients were subsequently treated according to standard protocols for local and systemic (adjuvant) treatment. For a more detailed description of the screening protocol ${ }^{10,25,28}$ see the online-only Appendix.

The records of all women with breast cancer detected before March 1, 2006, were inspected for the occurrence of a relapse and/or death (using the municipal registry) until January 1, 2009 (Figs 1 and Appendix Fig A1, online only).

\section{Statistical Analysis}

Overall breast cancer detection rates were calculated as the total number of breast cancers detected (including ductal carcinoma in situ [DCIS]) per 1,000 woman-years at risk; a Poisson distribution was assumed to calculate the 95\% CIs. Detection rates were compared using exact tests (based on the binomial distribution).

For each of the three screening modalities, we calculated sensitivity, specificity, and positive predictive value, including 95\% CIs based on the binomial distribution. The differences between sensitivity of screening modalities were tested by a McNemar's test. Sensitivity was compared between the different subgroups with the use of Fisher's exact test. For the analysis of the screening variables and for the comparison of the methods of detection of breast cancer, we used only the screening data that included the results of both imaging methods at the screening rounds $(\mathrm{n}=75$, Fig 1$)$.

Differences in proportion of interval cancers, age at diagnosis (continuous variable without normal distribution), DCIS or invasive cancer, tumor size (continuous variable without normal distribution), nodal status, histologic type, histologic grade, estrogen receptor, and progesterone receptor status between subgroups were analyzed by Fisher's exact, MannWhitney, or Kruskal-Wallis test. A two-sided $P$ value of lower than .05 was considered statistically significant. The cumulative distant metastasis-free and overall survival were calculated by using the Kaplan-Meier method. Statistical analyses were performed using SPSS (SPSS 16.0 for Windows, SPSS Institute, Chicago, IL) and STATA 11SE (Stata Corp, College Station, TX).

\section{RESULTS}

\section{Patients}

Of the 2,275 women included in the study, 118 did not meet the various inclusion criteria (Figs 1, A1). ${ }^{10,25}$ The 2,157 eligible women included 599 carriers of a pathogenic gene mutation in BRCA1 $(\mathrm{n}=422)$, BRCA2 $(\mathrm{n}=172)$, or PTEN/TP53 $(\mathrm{n}=5), 1,069$ women in the high-risk and 489 women in the moderate-risk group (Tables 1 and 2). Median follow-up time from entry was 4.9 years (mean, 4.0; range, 0.1 to 6.3 years), with 8,760 woman-years at risk. The mean age at entry was 40.1 years (range, 19 to 75 years) for the total study group, and 38.7, 40.0, 40.8, and 40.0 years for the subgroups of women with a BRCA1 mutation, a BRCA2 mutation, the high-risk, and the moderate-risk group, respectively. In the mutation carriers, high- and moderate-risk group, respectively, 22\%, 16\%, and 15\% had no previous breast cancer screening before study entry.

\section{Breast Cancers}

To March 1, 2006, a total of 98 malignant tumors were detected in 94 women (Fig 1). Of the 97 breast cancers, 78 (80\%) were invasive and $19(20 \%)$ were DCIS (Table 1); 78 breast cancers were detected by screening (15 in the first and 63 in subsequent screening rounds) and six by chance at prophylactic mastectomy. Ten of 13 interval cancers were found in BRCA1 mutation carriers. Nine of 13 interval cancers were detected within 1 year (median, 8; range, 3 to 10 months; Table 3 ) and four more than 1 year since last screening by imaging (Fig 1). The median tumor size of all invasive interval cancers was $20 \mathrm{~mm}(\mathrm{n}=12$; range, 12 to $50 \mathrm{~mm}$ ).

The overall rate of detection was 10.4 per 1,000 woman-years at risk (Table 2), with the highest rate in BRCA2 mutation carriers (39.2 per 1,000), which was due partly to the high incidence of DCIS in this subgroup $(7.4$ per 1,000$)$. No clear differences $(P=.50)$ in detection rates between the high- and moderate-risk groups were observed, as discussed before. ${ }^{29}$

\section{Screening Performance}

Considering only those 75 breast cancers (including 13 DCIS and nine interval cancers) with results of both imaging methods (Table 3 ), $32(43 \%)$ were detected only by MRI screening (16 of the 32 in mutation carriers); five of these were also detected by CBE. A total of 19 breast cancers (25\%) were detected by both MRI and mammography screening; five also by CBE. Twelve breast cancers (16\%) were detected only by mammography screening (including eight DCIS); one also by CBE. Three breast cancers were detected only by CBE screening (4\%). Nine (12\%) were true interval cancers. Tumor sizes of

\begin{tabular}{|c|c|c|c|c|c|c|c|c|c|c|}
\hline \multirow[b]{2}{*}{ Parameter } & \multirow{2}{*}{$\begin{array}{r}\text { No. of } \\
\text { Women }\end{array}$} & \multicolumn{3}{|c|}{ No. of Cancers Detected } & \multicolumn{3}{|c|}{ No. of Screen-Detected Cancers } & \multicolumn{3}{|c|}{ No. of Interval Cancers } \\
\hline & & Total & Invasive & DCIS & Total & Invasive & DCIS & Total & Invasive & DCIS \\
\hline \multicolumn{11}{|c|}{ Mutation carrier } \\
\hline BRCA1 & 422 & $35\left(4^{*}\right)$ & $31\left(2^{*}\right)$ & $4\left(2^{*}\right)$ & 21 & 19 & 2 & 10 & 10 & 0 \\
\hline$B R C A 2$ & 172 & $18\left(2^{*}\right)$ & 13 & $5\left(2^{*}\right)$ & 15 & 12 & 3 & 1 & 1 & 0 \\
\hline PTEN/TP53 & 5 & 1 & 0 & 1 & 1 & 0 & 1 & 0 & 0 & 0 \\
\hline \multicolumn{11}{|l|}{ Risk group } \\
\hline High & 1,069 & 27 & 23 & 4 & 26 & 22 & 4 & 1 & 1 & 0 \\
\hline Moderate & 489 & 16 & 11 & 5 & 15 & 11 & 4 & 1 & 0 & 1 \\
\hline Total & 2,157 & $97\left(6^{*}\right)$ & $78\left(2^{*}\right)$ & $19\left(4^{*}\right)$ & 78 & 64 & 14 & 13 & 12 & 1 \\
\hline $\begin{array}{l}\text { Abbreviations: } \\
\text { *Indicates No. } \\
\text { cancers, two D } \\
\text { included in the }\end{array}$ & $\begin{array}{l}\text { ductal carc } \\
\text { cers detec } \\
\text { BRCA1 } \mathrm{m} \\
\text { o. of breas }\end{array}$ & $\begin{array}{l}\text { in situ; } \\
\text { PM (in } \\
\text { carriers } \\
\text { ers dete }\end{array}$ & $\begin{array}{l}\text { rophylacti } \\
\text { thesis). Six } \\
\text { two breas } \\
\text { but not in }\end{array}$ & $\begin{array}{l}\text { ectomy. } \\
\text { t cancers } \\
\text { ers (two } \\
\text { in the } \mathrm{N}\end{array}$ & $\begin{array}{l}\text { detec } \\
\text { in } B R \\
\text { nterval }\end{array}$ & $\begin{array}{l}\text { a specime } \\
\text { nutation c } \\
\text { rs. }\end{array}$ & $\begin{array}{l}\mathrm{n} \text { a } \mathrm{PM} \\
\text { as indi }\end{array}$ & $\begin{array}{l}\text { breast } \\
\text { in pare }\end{array}$ & $\begin{array}{l}\text { rs (two inv } \\
\text { ses. These }\end{array}$ & $\begin{array}{l}\text { breast } \\
\text { ers are }\end{array}$ \\
\hline
\end{tabular}


Table 2. Detection of Breast Cancers (including ductal carcinoma in situ), Including Screen-Detected Cancers ( $\mathrm{n}=78$ ) and Interval Cancers ( $\mathrm{n}=13$ ),

\begin{tabular}{|c|c|c|c|c|c|c|c|c|}
\hline \multirow[b]{3}{*}{ Parameter } & \multirow{3}{*}{$\begin{array}{r}\text { No. of } \\
\text { Women }\end{array}$} & \multirow{3}{*}{$\begin{array}{c}\text { Woman-Years } \\
\text { at Risk }\end{array}$} & \multirow{2}{*}{\multicolumn{2}{|c|}{$\begin{array}{c}\text { No. of } \\
\text { Screen-Detected } \\
\text { and Interval } \\
\text { Cancers }\end{array}$}} & \multicolumn{4}{|c|}{ Rate of Detectiont } \\
\hline & & & & & All C & & Invasive & cers \\
\hline & & & Total & Invasive & Detection Rate & $95 \% \mathrm{Cl}$ & Detection Rate & $95 \% \mathrm{Cl}$ \\
\hline \multicolumn{9}{|l|}{ Mutation carrier } \\
\hline$B R C A 1$ & 422 & 1,178 & 31 & 29 & 26.3 & 17.9 to 37.3 & 24.6 & 16.5 to 35.3 \\
\hline$B R C A 2$ & 172 & 408 & 16 & 13 & 39.2 & 22.4 to 63.7 & 31.9 & 17.0 to 54.5 \\
\hline PTEN/TP53 & 5 & 13 & 1 & 0 & - & - & - & - \\
\hline \multicolumn{9}{|l|}{ Risk group } \\
\hline High & 1,069 & 4,838 & 27 & 23 & $5.6 \ddagger$ & 3.7 to 8.1 & $4.8 \ddagger$ & 3.0 to 7.1 \\
\hline Moderate & 489 & 2,324 & 16 & 11 & 6.9 & 3.9 to 11.2 & 4.7 & 2.4 to 8.5 \\
\hline Total & 2,157 & 8,760 & 91 & 76 & 10.4 & 8.4 to 12.8 & 8.7 & 6.8 to 10.9 \\
\hline
\end{tabular}

*The number of cancers and rates of detection are excluding the six cancers detected by chance at prophylactic mastectomy. Overall rates of detection (invasive plus in situ), when including the breast cancers detected at prophylactic mastectomy (in total 97 breast cancers, see Table 1), are 11.1, 29.7, and 44.1 per 1,000 woman-years at risk for the total study group, BRCA1 mutation carriers, and BRCA2 mutation carriers, respectively. Rates of detection of invasive cancers, including breast cancers detected at prophylactic mastectomy, are 8.9 and 26.3 per 1,000 woman-years at risk for the total study group and $B R C A 1$ mutation carriers, respectively.

†Rates shown are per 1,000 woman-years at risk.

‡Differences in rates of detection between the high- and moderate-risk group for all cancers $(P=.50)$ and invasive cancers $(P=1.0)$ are not significant.

invasive tumors were largest in the group of interval cancers (median size, $16.5 \mathrm{~mm}$ ) and smallest in the group of cancers detected by MRI only (median size, $9 \mathrm{~mm} ; P=.002$; Table 3 ). Age at diagnosis tended to be lower $(P<.10)$ in the patient group with interval cancers.

For all 75 breast cancers (invasive plus in situ), the sensitivity was $20.6 \%$ for CBE, $41.3 \%$ for mammography, and $70.7 \%$ for MRI, respectively (Table 4). The difference in sensitivity between mammography and MRI is significant $(P=.0016)$. Including only invasive cancers increased MRI sensitivity to $77.4 \%$ but decreased the mammography sensitivity to $35.5 \%(\mathrm{n}=62 ; P<.00005)$. In contrast, for DCIS cancers only, the sensitivity of mammography $(69.2 \%)$ was much higher than that of MRI sensitivity (38.5\%), but, due to small numbers, not significant ( $\mathrm{n}=13 ; P=.388$ ). The overall specificity was 97.9\% for CBE, $94.6 \%$ for mammography, and $89.7 \%$ for MRI.

Regarding women younger than 40 years of age at diagnosis, in five of 26 patients, the tumor was only detected by mammography (three patients with DCIS), while in 11 women the tumor was only detected by MRI (one patient with DCIS; Appendix Table A2, online only).

Looking more specifically at mutation carriers, the mammography sensitivity was significantly lower $(P=.04)$ in BRCA1 $(25.0 \%)$ than in BRCA2 mutation carriers (61.5\%). Strikingly, the sensitivity of MRI was much higher than that of mammography in BRCA1 $(\mathrm{n}=24$; $66.7 v 25.0 \% ; P=.0129)$ and only slightly higher $(\mathrm{n}=13 ; 69.2 v$

Table 3. Comparison of the Methods of Detection of Breast Cancer (using only the screening data that included the results of both imaging methods at the screening rounds, $\mathrm{n}=75$ )

\begin{tabular}{|c|c|c|c|c|c|c|}
\hline Parameter & $\begin{array}{c}\text { MRI Screening + } \\
\text { Mmg Screening - } \\
\text { CBE Screening + or - }\end{array}$ & $\begin{array}{c}\text { MRI Screening + } \\
\text { Mmg Screening + } \\
\text { CBE Screening + or - }\end{array}$ & $\begin{array}{c}\text { MRI Screening - } \\
\text { Mmg Screening + } \\
\text { CBE Screening + or - }\end{array}$ & $\begin{array}{l}\text { MRI Screening - } \\
\text { Mmg Screening - } \\
\text { CBE Screening + }\end{array}$ & $\begin{array}{l}\text { Interval } \\
\text { Cancers }\end{array}$ & $\begin{array}{l}\text { Total No. } \\
\text { of Breast } \\
\text { Cancers }\end{array}$ \\
\hline \multicolumn{7}{|l|}{ Mutation carrier } \\
\hline BRCA1 & 11 & 4 & $2(2)$ & 1 & 6 & $24(2)$ \\
\hline$B R C A 2$ & $4(1)$ & $5(1)$ & $3(1)$ & 0 & 1 & $13(3)$ \\
\hline PTEN & $1(1)$ & 0 & 0 & 0 & 0 & $1(1)$ \\
\hline \multicolumn{7}{|l|}{ Risk group } \\
\hline High & $9(1)$ & 8 & $2(1)$ & 2 & 1 & $22(2)$ \\
\hline Moderate & 7 & 2 & $5(4)$ & 0 & $1(1)$ & $15(5)$ \\
\hline Total & $32(3)$ & $19(1)$ & $12(8)$ & 3 & $9(1)$ & $75(13)$ \\
\hline $\begin{array}{l}\text { Median tumor size of invasive } \\
\text { tumors, } \mathrm{mm}\end{array}$ & 9 & 15 & 13.5 & 10.0 & 16.5 & 12.0 \\
\hline Range & $4-45$ & $4-35$ & $4-20$ & $5-10$ & $12-45$ & $4-45$ \\
\hline Invasive tumors $\leq 1 \mathrm{~cm}, \%$ & 62.1 & 33.3 & 25.0 & 100.0 & 0 & 45.2 \\
\hline Median age at diagnosis, years & 45.5 & 49.1 & 41.5 & 45.7 & 38.1 & 45.2 \\
\hline Range & $36-53$ & $27-68$ & $31-61$ & $32-49$ & $28-53$ & $27-68$ \\
\hline
\end{tabular}

NOTE. Numbers in parenthesis indicate ductal carcinoma in situ. The results have been calculated on the basis of data on 75 of the 97 cancers (Fig 1 ). A mammographic or MRI study with a Bi-RADS score of 3, 0, 4 or 5 and a clinical breast examination that was classified as uncertain or suspicious was defined as positive (+). A mammographic or MRI study with a Bi-RADS score of 1 or 2 and a clinical breast examination that was classified as not suspicious was defined as negative (-).

Abbreviations: MRI, magnetic resonance imaging; Mmg, mammography; CBE, clinical breast examination; Bi-RADS, Breast Imaging Reporting and Data System. 


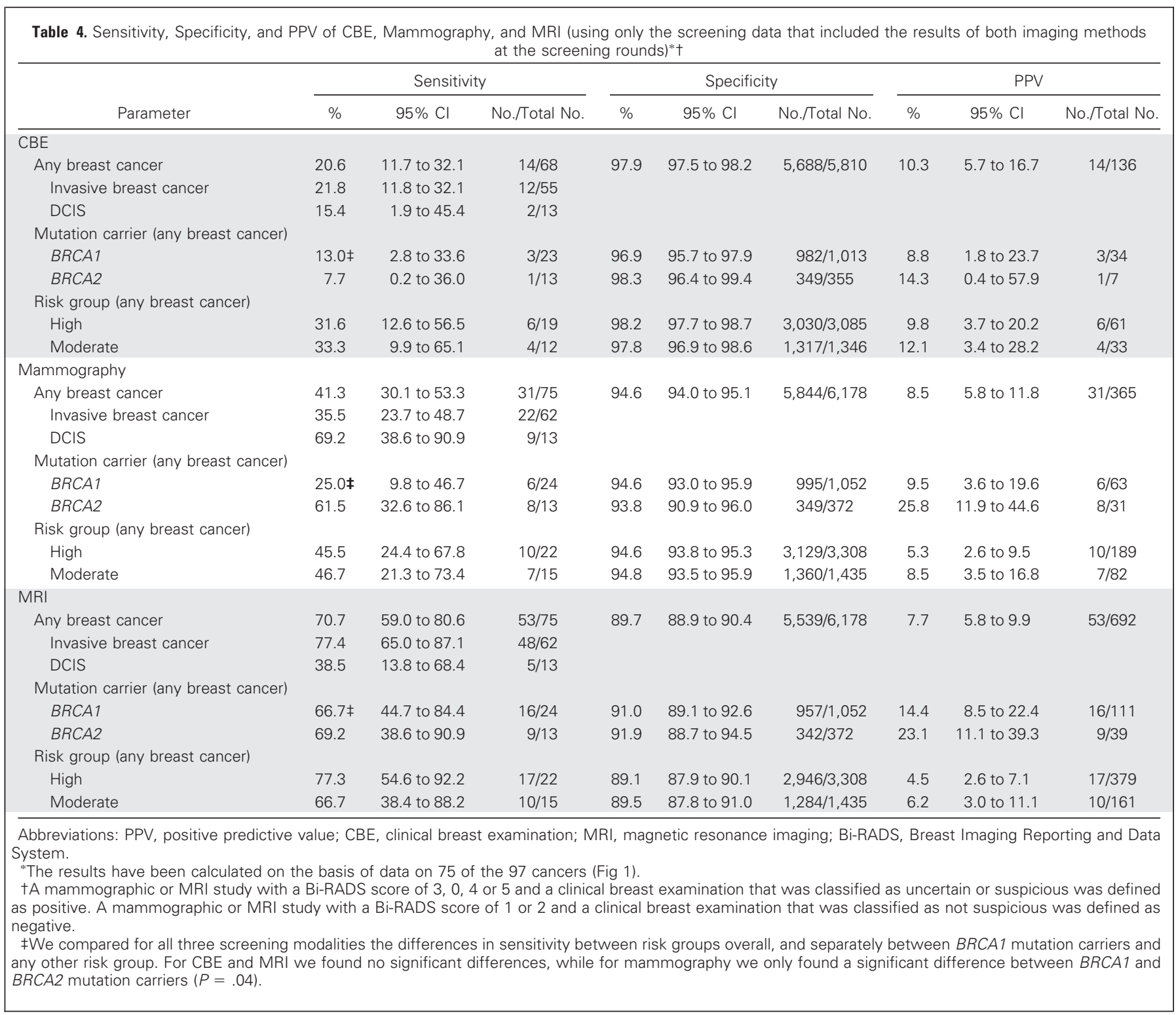

$61.5 \% ; P=1.0)$ in $B R C A 2$ mutation carriers. The sensitivity of CBE was highest in the high- and moderate-risk groups, but overall differences were not significant $(P=.22)$. The specificity of each screening method did not differ much between the risk groups.

\section{Patient and Tumor Characteristics}

The age at diagnosis (mean 44.4; median, 44.6; range, 27 to 68 years) differed overall significantly $(P=.0006)$ between the different risk groups (Table 5): $58.1 \%$ of the BRCA1 mutation carriers had an age at diagnosis of breast cancer younger than 40 years $(9.7 \%$ younger than 30 years of age), compared with $50.0 \%$ in BRCA2 mutation carriers, $18.5 \%$ in the high-risk group, and only $6.3 \%$ in the moderaterisk group.

Strikingly, DCIS was found in only $6.5 \%$ of the BRCA1associated tumors, in contrast to $18.8 \%$ of the BRCA2-associated cases, but differences between risk groups were not significant (Table 5). In BRCA1 mutation carriers, $35.7 \%$ of the invasive tumors were larger than $2 \mathrm{~cm}$ compared to only $7.7 \%$ in $B R C A 2$ mutation carriers. Both in BRCA2 mutation carriers and in women at high and moderate risk, a large proportion of the invasive tumors was smaller than $1 \mathrm{~cm}(61.5 \%, 40.9 \%$, and $63.6 \%$, respectively). The tumor sizes differed significantly between the four subgroups $(P=.003)$, and also between BRCA1 and BRCA2 mutation carriers separately $(P=.0045)$.

The distribution of nodal status did not differ between the different risk groups $(P=.42)$. Grade 1 tumors were mostly found in women at high or moderate risk ( $52.2 \%$ and $54.5 \%$, respectively). The women with a BRCA1 mutation had a high proportion of grade 3 tumors $(77.8 \%)$, in addition to a high percentage of tumors that were negative for steroid receptors.

\section{Disease-Free and Overall Survival}

The median follow-up from time of diagnosis of the primary tumors in the 89 surviving patients was 5.0 years (range, 1.7 to 8.4 
Table 5. Characteristics of Primary Breast Cancers Detected, Including Screen-Detected Cancers $(\mathrm{n}=78)$ and Interval Cancers ( $\mathrm{n}=13$ ), According to Risk Group* $\dagger$

\begin{tabular}{|c|c|c|c|c|c|c|c|c|c|c|c|c|}
\hline \multirow[b]{3}{*}{ Characteristic } & \multirow{2}{*}{\multicolumn{2}{|c|}{ BRCA1 }} & \multirow{2}{*}{\multicolumn{2}{|c|}{$B R C A 2$}} & \multicolumn{4}{|c|}{ Risk Group } & & & \multirow{2}{*}{\multicolumn{2}{|c|}{$P$}} \\
\hline & & & & & \multicolumn{2}{|c|}{ High } & \multicolumn{2}{|c|}{ Moderate } & \multicolumn{2}{|c|}{ Total } & & \\
\hline & No. & $\%$ & No. & $\%$ & No. & $\%$ & No. & $\%$ & No. & $\%$ & $\begin{array}{l}\text { Overall Comparison } \\
\text { Between Four Subgroups }\end{array}$ & $\begin{array}{c}\text { Comparison } \\
B R C A 1 \vee B R C A 2\end{array}$ \\
\hline No. of breast cancers detected & 31 & & 16 & & 27 & & 16 & & $91 \neq$ & & & \\
\hline No. of interval cancers & 10 & 32.3 & 1 & 6.3 & 1 & 3.7 & 1 & 6.3 & 13 & 14.3 & .01 & .07 \\
\hline \multicolumn{13}{|l|}{ Age at diagnosis, years } \\
\hline$<30$ & 3 & 9.7 & 0 & & 0 & & 0 & & 3 & 3.3 & & \\
\hline $30-39$ & 15 & 48.4 & 8 & 50.0 & 5 & 18.5 & 1 & 6.3 & $30 \ddagger$ & 33.0 & & \\
\hline $40-49$ & 9 & 29.0 & 6 & 37.5 & 10 & 37.0 & 10 & 62.5 & 35 & 38.5 & & \\
\hline $50-59$ & 4 & 12.9 & 1 & 6.3 & 9 & 33.3 & 4 & 25.0 & 18 & 19.8 & & \\
\hline$\geq 60$ & 0 & & 1 & 6.3 & 3 & 11.1 & 1 & 6.3 & 5 & 5.5 & .0006 & .29 \\
\hline \multicolumn{13}{|l|}{ Tumor size } \\
\hline DCIS & 2 & 6.5 & 3 & 18.8 & 4 & 14.8 & 5 & 31.3 & $15 \ddagger$ & 16.5 & .16 & $.32 \S$ \\
\hline \multicolumn{13}{|l|}{ Invasive tumors, $\mathrm{cm}$} \\
\hline$\leq 1$ & 6 & 21.4 & 8 & 61.5 & 9 & 40.9 & 7 & 63.6 & 30 & 40.5 & & \\
\hline $1-2$ & 12 & 42.9 & 4 & 30.8 & 10 & 45.5 & 3 & 27.3 & 29 & 39.2 & & \\
\hline$>2$ & 10 & 35.7 & 1 & 7.7 & 3 & 13.6 & 1 & 9.1 & 15 & 20.3 & .003 & .0045 \\
\hline \multicolumn{13}{|l|}{ Nodal status } \\
\hline Negative & 18 & 64.3 & 8 & 66.7 & 14 & 66.7 & 10 & 90.9 & 50 & 69.4 & & \\
\hline Positive & 10 & 35.7 & 4 & 33.3 & 7 & 33.3 & 1 & 9.1 & 22 & 30.6 & .42 & $1 \|$ \\
\hline \multicolumn{13}{|l|}{ Histologic type } \\
\hline Ductal & 24 & 85.7 & 10 & 76.9 & 17 & 73.9 & 8 & 72.7 & 59 & 78.7 & & \\
\hline Lobular & 0 & & 1 & 7.7 & 3 & 13.0 & 2 & 18.2 & 6 & 8.0 & & \\
\hline Tubular & 1 & 3.6 & 0 & & 2 & 8.7 & 1 & 9.1 & 4 & 5.3 & & \\
\hline Medullary & 3 & 10.7 & 2 & 15.4 & 0 & & 0 & & 5 & 6.7 & & \\
\hline Adenoid cystic & 0 & & 0 & & 1 & 4.3 & 0 & & 1 & 1.3 & .18 & .52 \\
\hline \multicolumn{13}{|l|}{ Histologic grade } \\
\hline 1 & 1 & 3.7 & 2 & 18.2 & 12 & 52.2 & 6 & 54.5 & 21 & 29.2 & & \\
\hline 2 & 5 & 18.5 & 3 & 27.3 & 10 & 43.5 & 5 & 45.5 & 23 & 31.9 & & \\
\hline 3 & 21 & 77.8 & 6 & 54.5 & 1 & 4.3 & 0 & & 28 & 38.9 & $<.001$ & .15 \\
\hline \multicolumn{13}{|l|}{ Estrogen receptor status } \\
\hline Positive & 5 & 17.9 & 7 & 63.6 & 19 & 86.4 & 10 & 90.9 & 41 & 56.9 & & \\
\hline Negative & 23 & 82.1 & 4 & 36.4 & 3 & 13.6 & 1 & 9.1 & 31 & 43.1 & $<.001$ & .02 \\
\hline \multicolumn{13}{|l|}{ Progesterone receptor status } \\
\hline Positive & 5 & 17.9 & 7 & 58.3 & 18 & 85.7 & 10 & 90.9 & 40 & 55.6 & & \\
\hline Negative & 23 & 82.1 & 5 & 41.7 & 3 & 14.3 & 1 & 9.1 & 32 & 44.4 & $<.001$ & .02 \\
\hline \multicolumn{13}{|c|}{$\begin{array}{l}\text { Abbreviation: DCIS, ductal carcinoma in situ. } \\
\text { *No. of cancers and characteristics of breast cancers detected are excluding six cancers detec } \\
\text { †Percentages are based on the numbers of women with known data; numbers with missing } \\
\text { łIncluding one DCIS in a PTEN mutation carrier. } \\
\S P=.68 \text { for the comparison between } B R C A 2 \text { mutation carriers and the moderate-risk group. } \\
\| P=.32 \text { for the comparison between BRCA2 mutation carriers and the moderate-risk group. }\end{array}$} \\
\hline
\end{tabular}

years). Eleven of 93 patients with breast cancer developed a recurrence: seven of 11 with a gene mutation (Appendix Table A3, online only). All but one were screen-detected tumors. Distant metastasis occurred in five patients (all BRCA1/2 mutation carriers), generally at a young age. The primary tumor sizes were $2,9,20,25$, and $40 \mathrm{~mm}$, and only one tumor was node positive. Four patients died (three of $31=9.7 \%$ of all $B R C A 1$ and one of $16=6.3 \%$ of all $B R C A 2$ mutation carriers). The cumulative distant-metastasis free and overall survival at 6 years in the $42 B R C A 1 / 2$ mutation carriers with invasive cancer were $83.9 \%$ (95\% CI, $64.1 \%$ to $93.3 \%$ ) and $92.7 \%$ (95\% CI, $79.0 \%$ to $97.6 \%$ ), respectively (Appendix Fig A2, online only). None of the 43 (non-BRCA1/2) patients in the high- and moderate-risk groups (34 with invasive cancer) developed distant metastasis or died $(100 \%$ cumulative survival). Four other patients (three with DCIS) developed only a local recurrence or new ipsilateral tumor and two others developed a contralateral breast cancer.

\section{DISCUSSION}

In our previous study, we compared tumor characteristics of detected breast cancers with those of age-matched symptomatic controls, concluding that intensive surveillance including MRI can detect breast cancer at an early stage. ${ }^{10}$ Our present data showing comparable results confirm that conclusion. Sensitivity and specificity of MRI screening showed no major differences between the four subgroups studied. In contrast, the sensitivity of mammography was significantly higher in $B R C A 2$ mutation carriers than in BRCA1 mutation carriers $(61.5 \% \vee 25.0 \% ; P=.04)$. This can at least partly be explained by the higher proportion of DCIS in BRCA2 than in BRCA1 mutation carriers and the fact that, in our study, mammography had a higher $(P=.033)$ sensitivity in DCIS $(69.2 \%)$ compared to invasive tumors $(35.5 \%)$. Based on a review by two experienced radiologists in the 
context of a quality control side study, a major contributing factor to false-negative MRI diagnoses was nonenhancing DCIS, not visible on the MRIs (even retrospectively). ${ }^{28}$ The gain of sensitivity of MRI over mammography was smaller in BRCA2 mutation carriers $(69.2 \% \mathrm{v}$ $61.5 \% ; P=1.0)$ than in the other subgroups, including BRCA1 mutation carriers $(66.7 \% \vee 25.0 \% ; P=.0129)$. A similar observation was made in a subgroup analysis and in a review of all images of all cancer cases within the MARIBS (Magnetic Resonance Imaging Breast Screening) study. ${ }^{12,20,30}$ Also in retrospect, only two of their six cases of DCIS were visible on MRI in contrast to all on mammography. ${ }^{30}$ These results are in contrast to those of Kuhl et al, ${ }^{13,16,31}$ which showed a high MRI sensitivity for DCIS (as well as for invasive cancer).

Several large prospective MRI screening studies with more than 18 breast cancers detected have been reported. ${ }^{10-21}$ These studies, including our update, show some variations in results, which might be caused by numerous differences in study populations and methods as recently extensively discussed by Leach ${ }^{20}$ and Klijn. ${ }^{21}$ Nevertheless, all studies concluded that the sensitivity of MRI (range, 68\% to 91\%) was approximately twice that of mammography (range, $32 \%$ to $40 \%$ ). In contrast, with the exception of one study, ${ }^{13}$ the specificity of MRI (range, $81 \%$ to $97 \%$ ) was lower than that of mammography (range, $93 \%$ to $100 \%$ ). Combination of MRI and mammography resulted in higher sensitivities (range, $80 \%$ to $94 \%$ ). ${ }^{17}$

In our study, overall $42.7 \%$ of the breast cancers were detected only by MRI screening (median, $9 \mathrm{~mm}$; with $62 \%$ of tumors $\leq 1 \mathrm{~cm}$, Table 3): $45.8 \%$ of the breast cancers in BRCA1 mutation carriers, $30.8 \%$ in BRCA2 mutation carriers, $40.9 \%$ in high-risk women, and $46.7 \%$ in moderate-risk women. These results, in combination with the detection of a favorable tumor stage (particularly in the moderaterisk group), support the recommendation of the American Cancer Society to use annual MRI screening not only for BRCA1/2 mutation carriers, but for all women with an approximately $20 \%$ to $25 \%$ or greater CLTR of breast cancer due to a familial predisposition. ${ }^{22} \mathrm{How}-$ ever, the cost-effectiveness of MRI screening ${ }^{29,32-34}$ should be evaluated for all risk groups separately.

Interestingly, due to our extensive update we were now able to demonstrate differences between $B R C A 1$ and $B R C A 2$ mutation carriers. Apart from lower mammography sensitivity (25.0\% $v 61.5 \%$; $P=.04), B R C A 1$ mutation carriers showed a higher proportion of interval cancers $(32 \% v 6 \% ; P=.07)$, a nonsignificantly lower proportion of DCIS $(6.5 \% \vee 18.8 \%)$ and a significant greater frequency $(P=.0045)$ of unfavorable tumor size $(>2 \mathrm{~cm})$ at diagnosis $(35.7 \% \mathrm{v}$ $7.7 \%)$. These relatively poor results in BRCA1 mutation carriers could be partly explained by different mammographic features ${ }^{35}$ and growth pattern (pushing margins), ${ }^{36}$ young age, and especially a rapid tumor growth in gene mutation carriers. ${ }^{30,37-38}$ Moreover, as in other studies, ${ }^{39-42}$ most of the invasive cancers in BRCA1 mutation carriers were high grade and estrogen receptor and progesterone receptor negative, tumor characteristics which are, in general, also associated with a more rapid tumor growth.

Our study is the first prospective study reporting mortality data to our knowledge. Strikingly all five women developing an incurable stage of disease (ie, distant metastases) were BRCA1/2 mutation carriers, including four women who died despite a favorable tumor stage $(\mathrm{T}<1 \mathrm{~cm}, \mathrm{~N} 0)$ in two of them. This observation underscores the need for medical counselors to avoid guaranteeing that all breast cancer deaths can be prevented by early detection of breast cancer as a result of screening. Nevertheless, the low mortality up to 8.4 years from diagnosis (median, 5.0 years) seems promising when compared to previous studies, ${ }^{40,43,44}$ with an overall survival of $93 \%$ at 6 years. Until now, breast cancer mortality reduction was simulated by predictive models based on tumor stage at time of detection. ${ }^{29,32-34,45}$ The optimal study design for demonstration of reduced mortality by intensive surveillance is a randomized controlled trial. However, in the absence of randomized studies currently and in the future (for ethical reasons), we compared the overall survival of our patients with 26 historical cohorts of patients traced from the literature and from our own institution in exploratory analyses (Appendix Fig A3, online only). ${ }^{44,46,47}$ These 26 cohorts comprise totally 1,081 BRCA1/2 (BRCA1: $\mathrm{n}=751 ; B R C A 2: \mathrm{n}=330$ ) mutation carriers (median, 42; range, 14 to 170 patients per cohort) and show a median overall survival of $74.5 \%$ (range, $50 \%$ to $95 \%$ ). The 5 -year cumulative overall survival was higher in our prospective MRISC series of patients (93\%; 95\% CI, 79\% to 98\%) than in our institutional historical unselected controls (170 BRCA1, 90 BRCA2) ${ }^{40,44}$ as well as in these 26 published series. Furthermore, no distant metastasis and deaths were observed in the high- and moderate-risk groups of our MRISC study. However, in view of the absence of randomization or correction for lead-time or for potential differences in treatment between studies, definite conclusions on survival effects of specific screening strategies cannot yet be made. Furthermore, cross-study comparisons of our observational results with those of historical controls from the literature have strong limitations in view of (possible) differences in populations, study periods, methodology, and breast cancer management.

In conclusion, the update of our study confirms that with a longer follow-up period ( $\approx 5$ years) the sensitivity of MRI is still strongly superior to that of mammography. In addition, and most strikingly, BRCA1-associated tumors behave completely differently from $B R C A 2$-associated tumors and those from the other risk groups in view of the younger age at diagnosis, lower mammographic sensitivity, the high proportion of interval cancers, the low proportion of DCIS, and unfavorable tumor size at diagnosis. A modification of the screening schedule for BRCA1 mutation carriers (eg, biannual MRI) or application of specific treatment regimens $^{48,49}$ or preventive measures ${ }^{5-8}$ (in view of two deaths in women with very small tumors) may therefore be necessary in order to further improve results on survival, which seem promising with the current screening schedule.

\section{AUTHORS' DISCLOSURES OF POTENTIAL CONFLICTS} OF INTEREST

The author(s) indicated no potential conflicts of interest.

\section{AUTHOR CONTRIBUTIONS}

Conception and design: Adriana J. Rijnsburger, Inge-Marie Obdeijn, Reinoutje Kaas, Madeleine M.A. Tilanus-Linthorst, Carla Boetes, Claudette E. Loo, Martin N.J.M. Wasser, Elisabeth Bergers, Theo Kok, Sara H. Muller, Hans Peterse, Rob A.E.M. Tollenaar, Nicoline Hoogerbrugge, Sybren Meijer, Carina C.M. Bartels, Caroline Seynaeve, Maartje J. Hooning, Mieke Kriege, Paul I. M. Schmitz, Jan C. Oosterwijk, Harry J. de Koning, Emiel J.T. Rutgers, Jan G.M. Klijn Financial support: Inge-Marie Obdeijn, Madeleine M.A. Tilanus-Linthorst, Harry J. de Koning, Jan G.M. Klijn 
Administrative support: Adriana J. Rijnsburger, Maartje J. Hooning, Mieke Kriege

Provision of study materials or patients: Inge-Marie Obdeijn, Reinoutje Kaas, Madeleine Tilanus-Linthorst, Carla Boetes, Claudette E. Loo, Martin N.J.M. Wasser, Elisabeth Bergers, Theo Kok, Sara H. Muller, Hans Peterse, Rob A.E.M. Tollenaar, Nicoline Hoogerbrugge, Sybren Meijer, Carina C.M. Bartels, Caroline Seynaeve, Jan C. Oosterwijk, Emiel J.T. Rutgers, Jan G.M. Klijn
Collection and assembly of data: Adriana J. Rijnsburger, Mieke Kriege, Jan G.M. Klijn

Data analysis and interpretation: Adriana J. Rijnsburger, Maartje J. Hooning, Mieke Kriege, Paul I. M. Schmitz, Harry J. de Koning, Jan G.M. Klijn

Manuscript writing: All authors

Final approval of manuscript: All authors

\section{REFERENCES}

1. Antoniou A, Pharoah PD, Narod $S$, et al: Average risks of breast and ovarian cancer associated with BRCA1 or BRCA2 mutations detected in case series unselected for family history: A combined analysis of 22 studies. Am J Hum Genet 72:1117-1130, 2003

2. King MC, Marks JH, Mandell JB: Breast and ovarian cancer risks due to inherited mutations in BRCA1 and BRCA2. Science 302:643-646, 2003

3. Ford D, Easton DF, Stratton M, et al: Genetic heterogeneity and penetrance analysis of the BRCA1 and BRCA2 genes in breast cancer families: The Breast Cancer Linkage Consortium. Am J Hum Genet 62:676-689, 1998

4. Claus EB, Risch N, Thompson WD: Autosomal dominant inheritance of early-onset breast cancer: Implications for risk prediction. Cancer 73:643651,1994

5. Meijers-Heijboer H, van Geel B, van Putten $W L$, et al: Breast cancer after prophylactic bilateral mastectomy in women with a BRCA1 or BRCA2 mutation. N Engl J Med 345:159-164, 2001

6. Rebbeck TR, Kauff ND, Domchek SM: Metaanalysis of risk reduction estimates associated with risk-reducing salpingo-oophorectomy in BRCA1 or BRCA2 mutation carriers. J Natl Cancer Inst 101:8087, 2009

7. Cuzick J, Powles T, Veronesi U, et al: Overview of the main outcomes in breast-cancer prevention trials. Lancet 361:296-300, 2003

8. Robson M, Offit K: Clinical practice: Management of an inherited predisposition to breast cancer. N Engl J Med 357:154-162, 2007

9. Metcalfe KA, Birenbaum-Carmeli D, Lubinski $J$, et al: International variation in rates of uptake of preventive options in BRCA1 and BRCA2 mutation carriers. Int J Cancer 122:2017-2022, 2008

10. Kriege $M$, Brekelmans $C T$, Boetes $C$, et al: Efficacy of MRI and mammography for breastcancer screening in women with a familial or genetic predisposition. N Engl J Med 351:427-437, 2004

11. Warner $E$, Plewes DB, Hill KA, et al: Surveillance of BRCA1 and BRCA2 mutation carriers with magnetic resonance imaging, ultrasound, mammography, and clinical breast examination. JAMA 292: 1317-1325, 2004

12. Leach $M O$, Boggis $C R$, Dixon $A K$, et al: Screening with magnetic resonance imaging and mammography of a UK population at high familial risk of breast cancer: A prospective multicentre cohort study (MARIBS). Lancet 365:1769-1778, 2005

13. Kuhl $C K$, Schrading $S$, Leutner $C C$, et al: Mammography, breast ultrasound, and magnetic resonance imaging for surveillance of women at high familial risk for breast cancer. J Clin Oncol 23:8469-8476, 2005

14. Hagen Al, Kvistad KA, Maehle L, et al: Sensitivity of MRI versus conventional screening in the diagnosis of BRCA-associated breast cancer in a national prospective series. Breast 16:367-374, 2007

15. Weinstein $S P$, Localio $A R$, Conant $E F$, et al: Multimodality screening of high-risk women: A prospective cohort study. J Clin Oncol 27:6124-6128, 2009

16. Kuhl C, Weigel S, Schrading S, et al: Prospective multicenter cohort study to refine management recommendations for women at elevated familial risk of breast cancer: The EVA trial. J Clin Oncol 28:1450-1457, 2010

17. Warner $E$, Messersmith $H$, Causer $P$, et al: Systematic review: Using magnetic resonance imaging to screen women at high risk for breast cancer. Ann Intern Med 148:671-679, 2008

18. Kriege M, Klijn JGM: Efficacy of MRI and mammography for breast cancer screening in women with genetic predisposition, American Society of Clinical Oncology, 2007 Educational Book. Alexandria, VA, American Society of Clinical Oncology, pp 135-141, 2007

19. Sardanelli F, Podo F: Breast MR imaging in women at high-risk of breast cancer. Is something changing in early breast cancer detection? Eur Radiol 17:873-887, 2007

20. Leach MO: Breast cancer screening in women at high risk using MRI. NMR Biomed 22:1727, 2009

21. Klijn JG: Early diagnosis of hereditary breast cancer by magnetic resonance imaging: What is realistic? J Clin Oncol 28:1441-1445, 2010

22. Saslow D, Boetes $C$, Burke W, et al: American Cancer Society guidelines for breast screening with MRI as an adjunct to mammography. CA Cancer J Clin 57:75-89, 2007

23. National Institute for Health and Clinical Excellence: Familial breast cancer. The classification and care of women at risk of familial breast cancer in primary, secondary and tertiary care. Update, July 2006. Available at: Http://www.nice.org.uk.

24. Nationaal Borstkanker Overleg Nederland: Richtlijn mammacarcinoom 2008. Available at: Http://www.cbo.nl.

25. Kriege M, Brekelmans CTM, Boetes $C$, et al: MRI screening for breast cancer in women with familial or genetic predisposition: Design of the Dutch National Study (MRISC). Fam Cancer 1:163168, 2001

26. Illustrated Breast Imaging Reporting and Data System (BI-RADS) (ed 3rd). Reston, VA, American College of Radiology, 1998

27. Liberman L, Menell JH: Breast imaging reporting and data system (BI-RADS). Radiol Clin North Am 40:409-430, 2002

28. Obdeijn IM, Loo CE, Rijnsburger AJ, et al: Assessment of false-negative cases of breast MR imaging in women with a familial or genetic predisposition. Breast Cancer Res Treat 119:399-407, 2010

29. Rijnsburger AJ: Effects and costs of breast cancer screening in women with a familial or genetic predisposition (thesis). Rotterdam, the Netherlands, 2005
30. Gilbert FJ, Warren RM, Kwan-Lim G, et al: Cancers in BRCA1 and BRCA2 carriers and in women at high risk for breast cancer: MR imaging and mammographic features. Radiology 252:358368, 2009

31. Kuhl CK, Schrading $S$, Bieling HB, et al: MRI for diagnosis of pure ductal carcinoma in situ: A prospective observational study. Lancet 370:485492, 2007

32. Plevritis SK, Kurian AW, Sigal BM, et al: Cost-effectiveness of screening BRCA1/2 mutation carriers with breast magnetic resonance imaging. JAMA 295:2374-2384, 2006

33. Griebsch I, Brown J, Boggis C, et al: Costeffectiveness of screening with contrast enhanced magnetic resonance imaging vs $\mathrm{X}$-ray mammography of women at a high familial risk of breast cancer. Br J Cancer 95:801-810, 2006

34. Norman RP, Evans DG, Easton DF, et al: The cost-utility of magnetic resonance imaging for breast cancer in BRCA1 mutation carriers aged 30-49. Eur J Health Econ 8:137-144, 2007

35. Kaas $R$, Kroger $R$, Peterse $J L$, et al: The correlation of mammographic-and histologic patterns of breast cancers in BRCA1 gene mutation carriers, compared to age-matched sporadic controls. Eur Radiol 16:2842-2848, 2006

36. Tilanus-Linthorst $M$, Verhoog $L$, Obdeijn $I M$, et al: A BRCA1/2 mutation, high breast density and prominent pushing margins of a tumor independently contribute to a frequent falsenegative mammography. Int J Cancer 102:91-95, 2002

37. Tilanus-Linthorst MMA, Kriege M, Boetes $C$, et al: Hereditary breast cancer growth rates and its impact on screening policy. Eur J Cancer 41:16101617, 2005

38. Tilanus-Linthorst MMA, Obdeijn I-M, Hop WCJ, et al: BRCA1 mutation and young age predict fast breast cancer growth in the Dutch, United Kingdom, and Canadian magnetic resonance imaging screening trials. Clin Cancer Res 13:7357-7362, 2007

39. Lakhani SR, Jacquemier J, Sloane JP, et al: Multifactorial analysis of differences between sporadic breast cancers and cancers involving BRCA1 and BRCA2 mutations. J Natl Cancer Inst 90:11381145, 1998

40. Brekelmans $C T$, Tilanus-Linthorst MM, Seynaeve $C$, et al: Tumour characteristics, survival and prognostic factors of hereditary breast cancer from BRCA2-, BRCA1- and non-BRCA1/2 families as compared to sporadic breast cancer cases. Eur J Cancer 43:867-876, 2007

41. Moller P, Evans DG, Reis MM, et al: Surveillance for familial breast cancer: Differences in outcome according to BRCA mutation status. Int J Cancer 121:1017-1020, 2007

42. Lakhani $S R$, Reis-Filho JS, Fulford $L$, et al: Prediction of BRCA1 status in patients with breast cancer using estrogen receptor and basal phenotype. Clin Cancer Res 11:5175-5180, 2005 
43. Verhoog LC, Brekelmans CT, Seynaeve C, et al: Survival and tumour characteristics of breastcancer patients with germline mutations of BRCA1. Lancet 351:316-321, 1998

44. Brekelmans CT, Seynaeve C, MenkePluymers $\mathrm{M}$, et al: Survival and prognostic factors in BRCA1-associated breast cancer. Ann Oncol 17: 391-400, 2006

45. Otto SJ, Fracheboud J, Looman CW, et al: Initiation of population-based mammography screening in Dutch municipalities and effect on breast-cancer mortality: A systematic review. Lancet 361:1411-1417, 2003

46. Chappuis PO, Rosenblatt J, Foulkes WD: The influence of familial and hereditary factors on the prognosis of breast cancer. Ann Oncol 10:11631170, 1999

47. Bonadona $V$, Dussart-Moser S, Voirin N, et al: Prognosis of early-onset breast cancer based on BRCA1/2 mutation status in a French population- based cohort and review. Breast Cancer Res Treat 101:233-245, 2007

48. Kriege M, Seynaeve C, Meijers-Heijboer $\mathrm{H}$, et al: Sensitivity to first-line chemotherapy for metastatic breast cancer in BRCA1 and BRCA2 mutation carriers. J Clin Oncol 27:3764-3771, 2009

49. Byrski T, Gronwald J, Huzarski T, et al: Pathologic complete response rates in young women with BRCA1-positive breast cancers after neoadjuvant chemotherapy. J Clin Oncol 28:375-379, 2010

\section{Get These JCO.org Tools Working for You}

- Access articles and abstracts, including archival issues from 1983 to today

- Browse content by subject category

- Link to citations from more than 1,300 HighWire-hosted journals

- Read articles online before they are issued in print

- Receive regular e-mail alerts on topics of interest

- Search throughout ASCO Annual Meeting abstracts

To subscribe or activate your online access, visit jco.org/subscriptions 